\title{
Reconstruction of Bilateral Buccal Mucosal Cancer Defects with a Bipedicle Anterolateral Thigh Flap-A Submental Approach
}

\author{
Kripa Shankar Mishra ${ }^{1, \odot}$ Rajan Arora ${ }^{1, \odot}$ Ravikiran Naalla ${ }^{1} \quad$ Saket Srivastava ${ }^{1, \odot}$
}

${ }^{1}$ Division of Reconstructive Microsurgery, Department of Surgical
Oncology, Rajiv Gandhi Cancer Institute and Research Center, New
Delhi, India

Indian J Plast Surg 2021;54:373-374.

Bilateral synchronous buccal mucosa cancer is an uncommon entity. Such defects have been reconstructed with two radial artery forearm-free (RAFF) flaps harvested either from bilateral or unilateral forearm. ${ }^{1,2}$ The disadvantages of this method are the requirement of two sets of anastomosis and a skin graft at the forearm donor site. A bipaddled anterolateral thigh (ALT) flap was described by Chen et al. ${ }^{3}$ wherein two flaps were harvested from a single donor site
Address for correspondence Ravikiran Naalla, MCh, Division of Reconstructive Microsurgery, Department of Surgical Oncology, Rajiv Gandhi Cancer Institute and Research Center, Room-3064, Sector 5, Rohini, New Delhi, India (e-mail: ravi_2488@yahoo.co.in).

on a common pedicle for anastomoses. In this technique, the distal skin paddle with the longer perforator was used to resurface the buccal mucosa, contralateral to the anastomosis site. The lower gingivolabial sulcus (LGLS) was cut opened to accommodate the perforator (bridge segment), perfusing the distal skin paddle. The location of the bridge segment was between the lip skin and mandible.

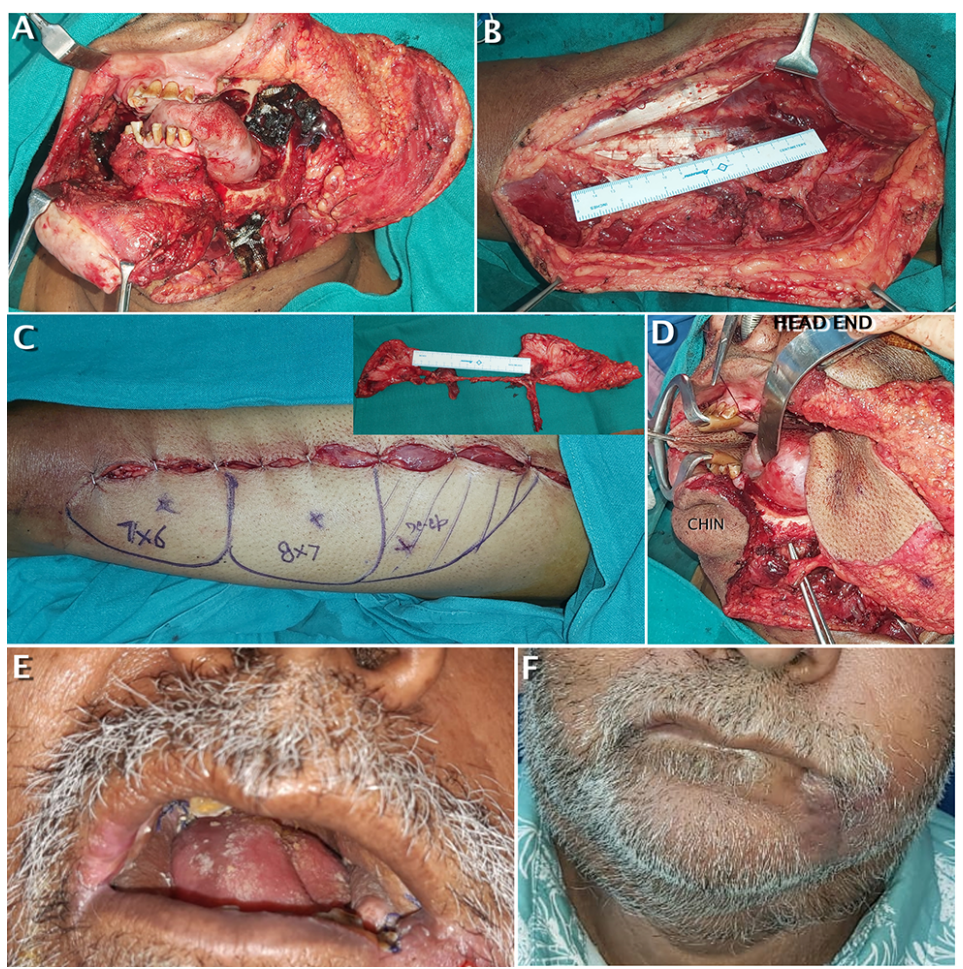

Fig. 1 (A) Bilateral buccal mucosal defects $7 \times 6 \mathrm{~cm}$ and $8 \times 7$ in a 50-year male. (B) Descending branch of lateral circumflex femoral vessels and its perforators nourishing the anterolateral thigh (ALT) flap. (C) The flap design (inset image shows the flap after pedicle division) showing skin paddles, and the marked region of the proximal skin paddle was deepithelized. (D) Before the inset the proximal paddle was placed over the left side defect, the distal paddle was tunneled across the submental region to reach the right-side defect (forceps points the tunneled perforator). (E, F) Well-settled flaps.

published online

September 2, 2021
DOI https://doi.org/

$10.1055 / \mathrm{s}-0041-1734575$

ISSN 0970-0358 (c) 2021. Association of Plastic Surgeons of India.

This is an open access article published by Thieme under the terms of the Creative Commons Attribution-NonDerivative-NonCommercial-License, permitting copying and reproduction so long as the original work is given appropriate credit. Contents may not be used for commercial purposes, or adapted, remixed, transformed or built upon. (https://creativecommons.org/licenses/by-nc-nd/4.0/).

Thieme Medical and Scientific Publishers Pvt. Ltd. A-12, 2nd Floor, Sector 2, Noida-201301 UP, India 
In our modification ( - Fig. 1 ), the distal skin paddle along with the perforator was tunneled across the submental region instead of accessing the LGLS. By this approach, we can either preserve the lower lip integrity or perform a meticulous repair of the LGLS, if it was already split by the oncosurgeon. Shallowing of the LGLS has led to drooling of saliva in the Chen et al series, which can be avoided with the submental technique. ${ }^{3}$ The submental region can accommodate a perforator with a muscle cuff, whereas LGLS location might lead to either compression of the perforator or shallowing of LGLS. The prerequisites for performing this procedure are suitable perforator anatomy and the skill of intramuscular perforator dissection. This technique is feasible only in patients who undergo bilateral neck dissection. Contralateral neck dissection facilitates the distal flap tunneling and inset. In contralateral buccal mucosal defects following a submucous fibrosis (SMF) release without neck dissection, a LGLS incision approach would be preferred.

\section{Conflict of Interest}

None declared.

\section{References}

1 Wei FC, Chang YM, Kildal M, Tsang WS, Chen HC. Bilateral small radial forearm flaps for the reconstruction of buccal mucosa after surgical release of submucosal fibrosis: a new, reliable approach. Plast Reconstr Surg 2001;107(7):1679-1683

2 Tsao CK, Wei FC, Chang YM, et al. Reconstruction of the buccal mucosa following release for submucous fibrosis using two radial forearm flaps from a single donor site. J Plast Reconstr Aesthet Surg 2010;63(7):1117-1123

3 Chen WC, Changchien CH, Su YM. Bipaddled anterolateral thigh perforator flap for simultaneous reconstruction of bilateral buccal defects following oral cancer ablation or release of oral submucous fibrosis. J Surg Case Rep 2016;2016(9):154 